\title{
Author Correction: Digital Citizenship: you Can't Go Home Again
}

\author{
Randy Hollandsworth $^{1}$ (D) Judy Donovan ${ }^{2} \cdot$ Mary Welch $^{3}$
}

Published online: 9 October 2017

(C) Association for Educational Communications \& Technology 2017

\section{Author Correction: TechTrends (2017)}

https://doi.org/10.1007/s11528-017-

0190-4

The original version of this article unfortunately contained a mistake. Figure 3 on the published version of the article was wrong. The correct Fig. 3 is now presented below.

The online version of the original article can be found at https://doi.org/ 10.1007/s11528-017-0190-4

$\triangle$ Randy Hollandsworth

rhollandsworth@piedmont.edu

Judy Donovan

judy.donovan@ashford.edu

Mary Welch

mwelch@piedmont.edu

1 Piedmont College, 1021 Central Avenue-Lane Hall,

Demorest, GA 30353, USA

2 Ashford University, 8620 Spectrum Center Blvd., San Diego, CA 48060, USA

3 Piedmont College, 1021 Central Avenue, Demorest, GA 30535, USA 
Fig. 3 Proposed grade when digital citizenship should first be taught in school (Hollandsworth et al. 2011)
Grade that Digital Citizenship Should be Taught

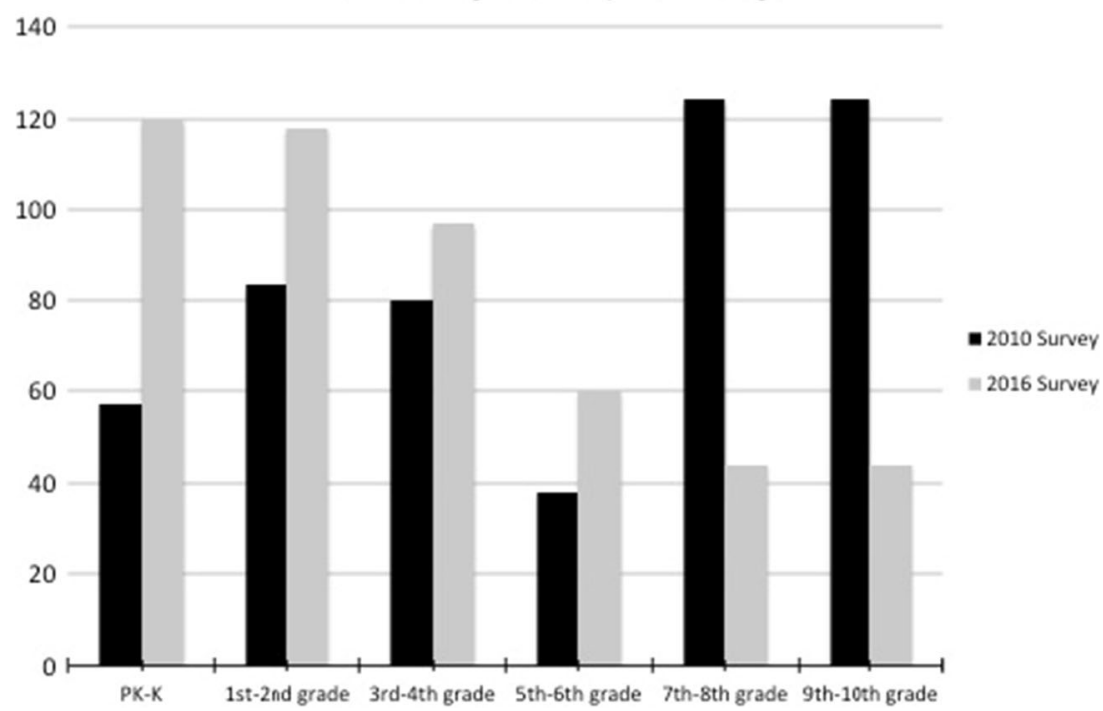

